Discussion Paper No. 13-112

The Metal Resources (METRO) Model.

A Dynamic Partial Equilibrium

Model for Metal Markets Applied

to Rare Earth Elements

Frank Pothen

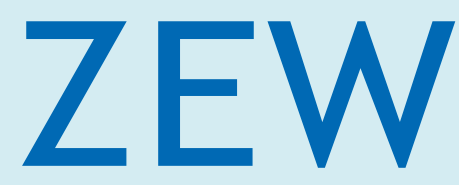

Zentrum für Europäische Wirtschaftsforschung $\mathrm{GmbH}$

Centre for European

Economic Research 
Discussion Paper No. 13-112

\title{
The Metal Resources (METRO) Model. A Dynamic Partial Equilibrium Model for Metal Markets Applied to Rare Earth Elements
}

\author{
Frank Pothen
}

Download this ZEW Discussion Paper from our ftp server:

http://ftp.zew.de/pub/zew-docs/dp/dp13112.pdf

Die Discussion Papers dienen einer möglichst schnellen Verbreitung von neueren Forschungsarbeiten des ZEW. Die Beiträge liegen in alleiniger Verantwortung der Autoren und stellen nicht notwendigerweise die Meinung des ZEW dar. 


\title{
The Metal Resources (METRO) Model. A Dynamic Partial Equilibrium Model for Metal Markets Applied to Rare Earth Elements
}

\author{
Frank Pothen*
}

December 18, 2013

\begin{abstract}
This paper presents the METal ResOurces (METRO) model, a partial equilibrium model tailored for metal markets. It allows for a disaggregated representation of the mining sector and endogenous investment in extractive capacities. It can be calibrated to a large number of metal markets. Rare Earth Elements are the first group of metals for which the model is implemented. A new dataset on Rare Earth mines is compiled to calibrate it. First results on key developments of Rare Earth markets are presented. Extensive sensitivity analyses indicate their robustness.
\end{abstract}

\section{Acknowledgements}

I am deeply indebted to Florian Landis, Simon Koesler, Heinz Welsch, Andreas Löschel, Sherman Robinson as well as the participants of the EcoMod 2012 Conference for their valuable feedback on earlier versions of this paper.

The research underlying this study was conducted within the project "Linking Impact Assessment Instruments to Sustainability Expertise (LIAISE)" funded by the European Commission, DG Research as part of the 7th Framework Programme, Grant Agreement 243 826. For more information on financial support, please visit the website of the author (www.zew.de/staff_fpo) and see the annual report of the Centre for European Economic Research

JEL Classifications: F17, Q31, Q37

Keywords: Partial Equilibrium Model, Metals, Rare Earths, Exhaustible Resources

*email: pothen@zew.de, tel: +49-621-1235-368, fax: +49-621-1235-226, ZEW, Centre for European Economic Research, Postfach 103443, L 7/1, 68034 Mannheim, Germany. (www.zew.de). 


\section{Introduction}

Metals and minerals have (re-) gained lively interest by policy makers, scientists, and the public in recent years. This interest has a diverse background. Prices of many metals have increased strongly after 2003 and growing protectionism has caused concerns about the security of supply with raw materials, both in the US and the EU (U.S. Department of Energy, 2011; EU Commission, 2010). Considerable environmental burdens from mining (Dudka and Adriano, 1997) and the perception that humanity over-exploits natural resources gave rise to the notion that resources need to be used more efficiently (EU Commission, 2011). Quantitative economic analyses of these topics necessitate a tailored modeling framework. The first aim of this study is to provide such a framework for metals.

Its second aim is to calibrate the model on Rare Earth Elements. Rare Earths are a group of 17 metals indispensable in a diverse number of high tech applications including catalysts for fuel cracking, high performance permanent magnets, and phosphors in TV screens. Rare Earths are the most notorious example of the debate on security of supply with raw materials. The US, the EU, and Japan are dependent on Rare Earth imports from China, which heavily restricts their exports. A number of non-Chinese mining firms currently attempt to enter the market. Analyses of the dynamics on Rare Earth markets necessitate considering endogenous investment and a firm-level replication of the mining sector. Thus, Rare Earths are an excellent first subject of study for the model presented in this paper.

The model is closely related to three streams of economic literature. Firstly, to econometric investigations of metal markets. Aggregate behavioral equations for supply, demand, price formation, and recycling are proposed in these studies. Parameters of the equations are estimated using historical data. They can be interpreted, tested statistically and counterfactual analyses can be conducted. Examples include Fisher et al. (1972); Fisher and Owen (1981); Slade (1980) and, more recently, Agostini (2006). The second literature stream calibrates partial equilibrium models on metal markets. Lanz et al. (2013) can serve as an example. They analyze the global copper market taking into account transportation costs, recycling and a disaggregated processing sector to assess the effects of sub-global climate policy on carbon leakage in the copper industry. Winters (1995) as well as Demailly and Quirion (2008) employ calibrated models to the steel sector. The third literature stream with which the METRO model shares similarities is energy system models allowing for a disaggregate representation of electricity generation (E3Mlab, 2010).

The paper extends the literature in two directions. It presents the METal ResOurces 
(METRO) model, a dynamic partial equilibrium model developed to analyze metals and their markets. It depicts the life cycle of a metal beginning with resources in the ground and their extraction, over processing, fabrication of final products to recycling or disposal. The mining sector consists of individual mines which invest endogenously in capacities. This modeling framework has, to my knowledge, never been applied to metal markets. Secondly, a new dataset on Rare Earths is compiled to calibrate the model.

The model is applied to simulate developments of supply, demand, and prices on Rare Earth markets. Simulations reveal that non-Chinese mining capacities will grow substantially until 2020. Rare Earth prices are expected to fall from 2016 onwards. Price differences between China and the rest of the world are considerably larger and more persistent for Heavy than for Light Rare Earths. They are not expected to fall below $10 \%$ before 2019 for Heavy Rare Earths. Comprehensive sensitivity checks indicate that these results are robust.

The paper proceeds as follows. Section 2 gives an overview on Rare Earths and their markets. The theoretical setup of the METRO model is presented in section 3. Section 4 discusses the data used to calibrate the model. Model results are shown in section 5 . Outcomes of sensitivity analyses are presented in section 6 . Section 7 concludes.

\section{Rare Earth Elements: Their Properties, their Markets, Applications}

Rare Earths are a collective term for a group of 17 metals. The Lanthanides, the elements ranging from Lanthanum (Number 57 in the periodic table of elements) to Lutetium (71), as well as Scandium (21) and Yttrium (39). They are often divided into two subgroups, the Light Rare Earths and the Heavy Rare Earths. The former include the Elements from Lanthanum (57) to Samarium (62), while the latter consist of Europium (63) to Lutetium (71). Yttrium is included in the Heavy Rare Earths due to its greater similarity to them.

All Rare Earths share similar chemical properties, which makes separating them challenging from a technical point of view and costly from an economic one. Their similarity is also the reason why they usually occur together in deposits, to a varying degree however. Unlike what their name suggests, Rare Earths are not rare from a geological point of view. The most abundant Rare Earth, Cerium, is roughly as abundant in the Earth's crust as copper. Even the rarest stable Rare Earth, Lutetium, is more abundant than Gold or Platinum. Rare Earths attain their rarity from the fact that they rarely occur 
in concentrations big enough to make their extraction profitable. Light Rare Earths are more abundant than Heavy Rare Earths, however.

Currently, China supplies the lion's share of Rare Earths. In 2001, it accounted for about $97 \%$ of the world production (U.S. Geological Survey, 2012b). This was not always the case. From the mid-1960s to the mid-1980s, the Mountain Pass mine in California has been the most important source of Rare Earths worldwide. China entered the market in the late 1970s when commencing extraction of Rare Earths from the Bayan Obo mine in the Inner Mongolia Autonomous Region, where they are won as a by-product of iron ore mining. Other important mining areas for Rare Earths are found in Sichuan and in the southern provinces of Fujian, Guangdong and Jiangxi (Tse, 2011). China has further increased its output of Rare Earths over time, eventually forcing foreign competitors to exit the market (Hurst, 2010). Figure 1 illustrates the production of Rare Earths in metric tons per year (tpa) by region from 1960 onwards. Besides Chinese mines, some fringe producers supply minor amounts of Rare Earths. Recycling does not play a relevant role on the supply side today (UNEP, 2011).

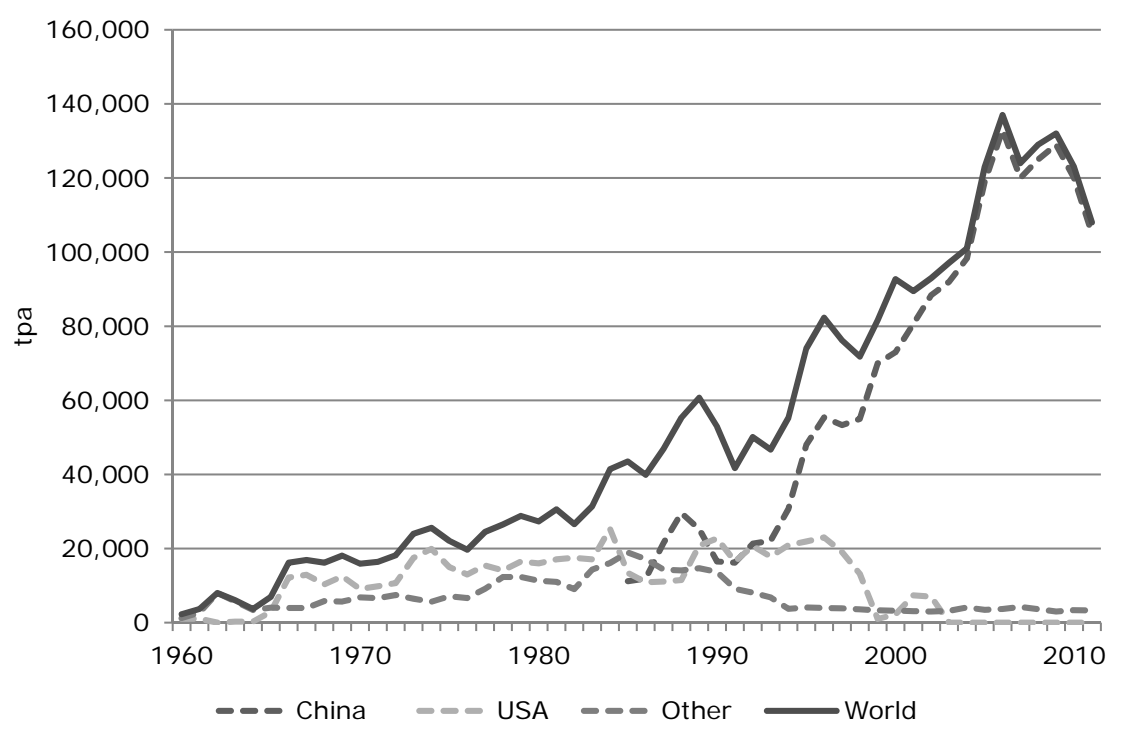

Figure 1: Global Rare Earth production by region in t Source: U.S. Geological Survey (2012a)

While current production of Rare Earths is highly concentrated in China, reserves are distributed much more widely. U.S. Geological Survey (2012b) estimates total reserves of Rare Earths at 110 million metric tons, only $48 \%$ of which are located in China. The Chinese government estimates its share of reserves to be much smaller, at approximately 23\% (SCIO, 2012). Important deposits are found in the Commonwealth of Independent States, the US, India, or Australia. By the end of July 2013, 52 projects outside China were 
at least at the stage where they had estimated their resources by international standards (Hatch, 2013b). This indicates a potentially much more dispersed supply in the future.

Rare Earths serve as an important input for a multiplicity of different products. U.S. Geological Survey (2011) distinguishes eight areas of application, listed in table 1. To make the applications more tangible, exemplary products are listed in the second column. Column three states the amount of Rare Earths used in this application in 2008, measured in tpa of Rare Earth Oxides (REO). The applications differ considerably in the individual Rare Earths needed. To give an impression of that, column four shows the share of Heavy Rare Earth Oxides (HREO) in each application in per cent.

\begin{tabular}{llll} 
Application & Exemplary Products & tpa REO & HREO \\
\hline & & & \\
Catalysts & Catalysts for fluid cracking, automotive catalysts & 27,380 & $0 \%$ \\
Glass industry & Polishing powders, colorized or decolorized glass & 28,444 & $3 \%$ \\
Metallurgy & Steel and aluminum alloys & 11,503 & $0 \%$ \\
Phosphors & TV sets, monitors, fluorescent lamps & 9,002 & $81 \%$ \\
Magnets & Permanent magnets in hard discs, wind turbines & 26,228 & $7 \%$ \\
Battery alloys & Nickel-metal-hydride (NiMH) batteries & 12,098 & $0 \%$ \\
Ceramics & Superconductors, Ceramic capacitors & 7,000 & $53 \%$ \\
Other & Paints and pigments, waste water treatment & 7,520 & $21 \%$ \\
& & & \\
\hline
\end{tabular}

Table 1: Most important applications of Rare Earths

Source: Schüler et al. (2011); U.S. Geological Survey (2011)

The demand for Rare Earths has grown dynamically over the last decades and is expected to further increase in the future. The most well-known and widely cited demand projections are the IMCOA / CREME prognoses by Dudley Kingsnorth. In Kingsnorth (2012), he estimates the overall demand for Rare Earths to grow from 105.000 tpa in 2011 to 160.000 tpa in 2016. The applications are expected to exhibit different growth rates ranging from $2-4 \%$ for catalysts to $8-12 \%$ for magnets.

Already in 1990, the Chinese government declared Rare Earths to be a strategic mineral. Foreign firms are banned from all mining, smelting, and separating activities, unless they form a joint venture with a Chinese company. Exports of Rare Earths are restricted using two main instruments.

The first instrument is ad valorem export tariffs. China levies between $15 \%$ and $25 \%$ on exports of Rare Earths. In 2007, the Chinese government additionally abolished the $16 \%$ value added tax refund on exports of unprocessed Rare Earths (Korinek and Kim, 2010). Thus, effective export taxes range between 34.5 and $46 \%$.

The second instrument is export quotas. Figure 2 shows how quotas have developed 
from 2005 onwards. They were reduced stepwise from about 65,000 tpa in 2005 to about 30,000 tpa in 2010 and held almost constant afterwards. The most notable change in recent years was the introduction of separate export quotas for Light and Heavy Rare Earths in 2012 (Tse, 2011). Quotas remained almost unaltered in 2013 (Hatch, 2013a). The Ministry of Commerce (MOFCOM) allocates export licenses. China is accused of using the licensing system to enforce minimum export prices (WTO, 2012). A significant share of Rare Earths exported was smuggled out of China (Hurst, 2010), the quantities exported illegally appear to decline, however (Wübbeke, 2013).

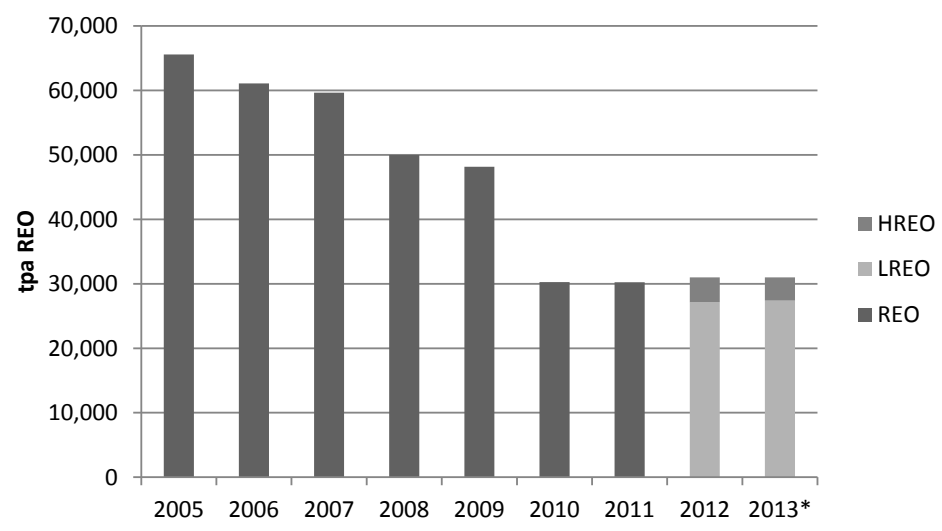

Figure 2: Chinese export quotas 2005 to 2013.

Source: Tse (2011); Hatch (2012b,c, 2013a)

Prices of Light Rare Earth Oxides (LREO) and Heavy Rare Earth Oxides (HREO) in US\$ per kg are shown in figure 3. They were at a low level in 2006 but increased visibly around 2008. After prices fell in 2009, they recovered around 2010 and skyrocketed in 2011. After this spike, prices reverted but remained substantially above long term averages. The differences between Rare Earths prices inside and outside China are large. They exceeded 100 per cent for most months from August 2010 to the end of 2011 (Light Rare Earths) or the end of 2012 (Heavy Rare Earths).

\section{Model Setup}

\subsection{Model Structure}

This section presents the theoretical setup of the METRO model, a dynamic partial equilibrium model incorporating the key aspects of metal sectors. The model is applicable to all metals, but most informative for those which are not only produced as by-products 


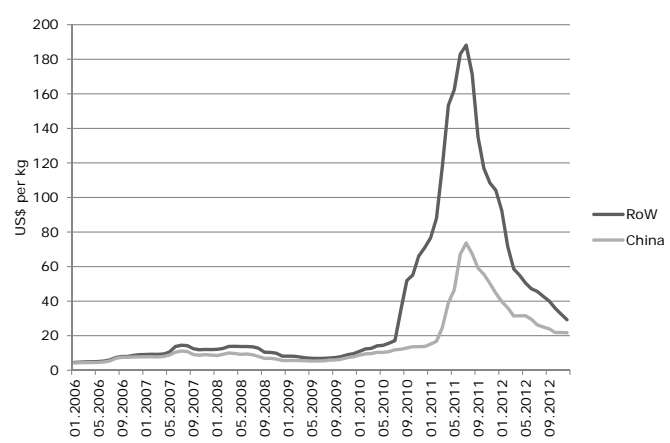

(a)

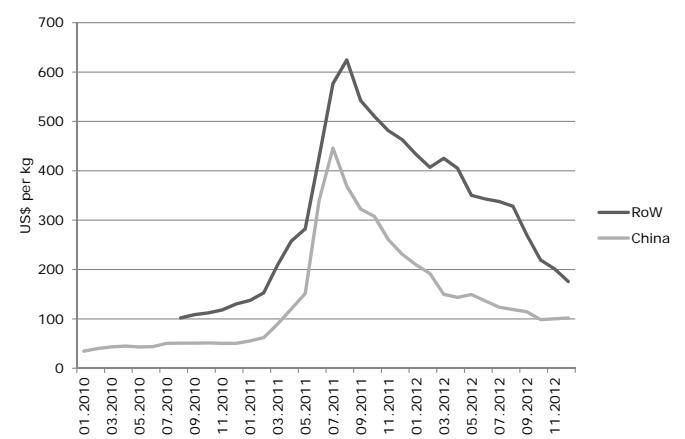

(b)

Figure 3: Real Prices of LREO and HREO in US\$ per $\mathrm{kg}$

Source: asianmetal.com

of other mining activities. The details outlined in this section match the specification used for Rare Earth Elements.

The structure of the model is presented for a region $r$ in figure 4. The whole physical life-cycle of metals is covered by the METRO model. I assume a finite number of resources stocks $^{1}$, each of which is owned by a mining company (mine). The mining sector in figure 4 is dotted to reflect that it consists of a number of firms. A mine invests in capacities, extracts ores and processes them into internationally tradeable goods. Processing of the metals can be modeled separately if necessary (Lanz et al., 2013). Trade sectors depict trade flows of the metals. They buy metals from domestic mines in other regions (import and export flows) and sell them to domestic industries. Transport and other trade costs, tariffs and quantitative trade restrictions can be implemented. Demand functions depict the demand from industries processing the metals into final goods. The model distinguishes between industries, which is indicated by printing the the demand sector in figure 4 dotted. When the goods made out of the metals reach the end of their useful lifetime, they are either discarded and lost economically or they are recycled and re-enter the life cycle at the trading sector.

In the application for Rare Earths, the model distinguishes five regions $r$. China $(\mathrm{Cn})$, the rest of Asia (AnC), the United States (USA), Europe (EU), and Other Countries (OtC). The model simulates Rare Earth markets up to 2025, results are displayed until 2020. The year is denoted $t$ in the model. METRO is formulated as a Mixed Complementarity Problem (MCP) in GAMS and solved using the Path algorithm (Dirkse and Ferris,

\footnotetext{
${ }^{1}$ I do not differentiate between resources and reserves in the description. This distinction is endogenous to the model.
} 


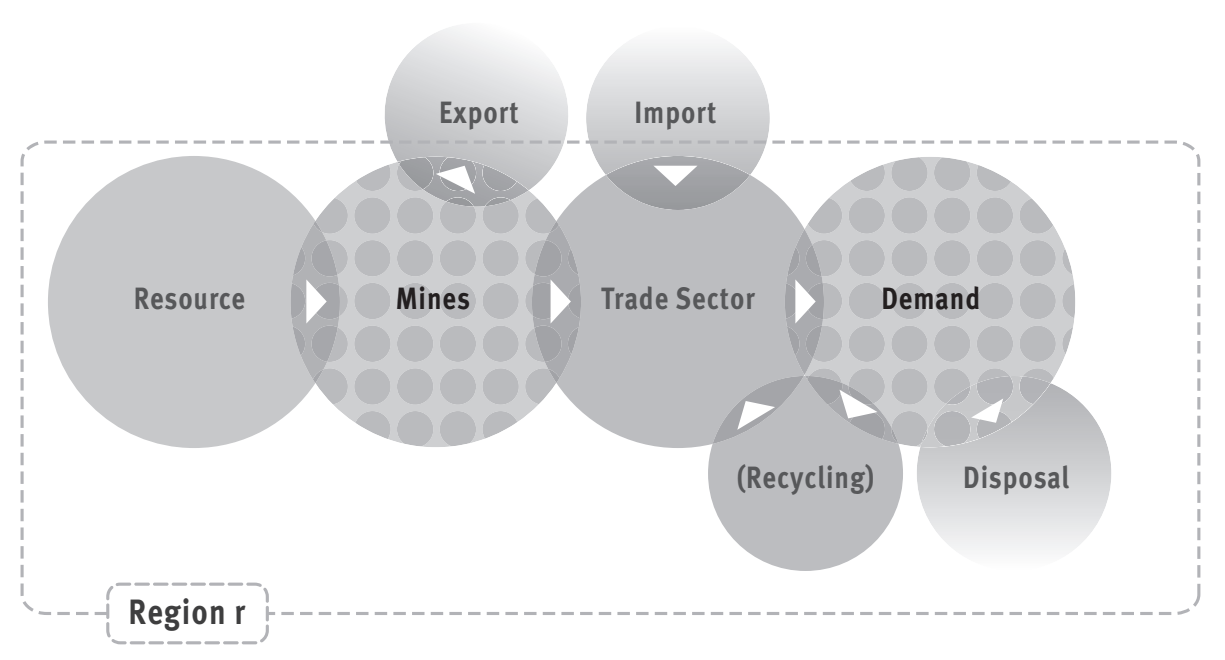

Figure 4: Model structure

1995). Behavioral assumptions of the sectors covered by the model are presented in the following subsections. To foster readability, all endogenous variables are printed in bold, while exogenous parameters and sets are printed in italics throughout the paper.

As common in the Rare Earth sector, all quantities are measured in (metric) tons of Rare Earth Oxides (REO). Specific Rare Earth Oxides are indexed by reo throughout the paper. Light and Heavy Rare Earth Oxides are denoted lreo and hreo, respectively. I exclude the only Rare Earth without stable isotopes, Promethium, from the analysis as it occurs only in trace amounts. Scandium as well as Holmium to Lutetium are also excluded due to a lack of data.

\subsection{Mining Sector}

Let us assume that the mining sector in region $r$ consists of a finite number of small, profitmaximizing mining companies $(m n)$ each of which decides on its investment in capacities $\Delta \mathbf{C a p}_{t}^{m n}$ and its extraction of ores $\mathbf{e x}_{t}^{m n}$ in each year $t$. Mine $m n$ owns a fixed and known resource stock $R^{m n}$. The parameter $\alpha^{r e o, m n}$ denotes the share of Rare Earth reo in the resource stock.

Mining companies enjoy revenues from selling Rare Earths and, if available, from byproducts. The producer price of Rare Earth reo in region $r$ is denoted $\mathbf{p} \mathbf{M N} \mathbf{N}_{r, t}^{r e o}$. The mine receives a weighted sum of producer prices for its extraction $\mathbf{e x}_{t}^{m n}$. Weights are given by the share of individual Rare Earths in the mine's ore $\left(\alpha^{r e o, m n}\right)$. Revenues from by-products per unit of extraction $\mathbf{e x}_{t}^{m n}$ are denoted $\mu^{m n} \cdot \mu^{m n}$ is specific to each mine but held constant over time, implying exogenous and constant prices of by-products.

Extraction costs are assumed to be linear (Agostini, 2006) and denoted $c^{m n}$. Costs 
of investment in capacity are characterized by the convex investment cost function $c \operatorname{Inv}^{m n}\left(\boldsymbol{\Delta} \mathbf{C a p}_{0}^{m n}, \ldots, \boldsymbol{\Delta} \mathbf{C a p}_{t}^{m n}, \ldots, \boldsymbol{\Delta} \mathbf{C a p}_{T}^{m n}\right)$ which is specified in detail below.

Mine $m n$ maximizes its profits over all years $t \in T=\{2014, \ldots, 2025\}$ according to equation (1). They take Rare Earth prices $\mathbf{p} \mathbf{M} \mathbf{N}_{r, t}^{r e o}$ as given, reflecting that new Rare Earth mines will be run by small junior mining companies unable to gain market power in the short run.

Mining firms are assumed to have perfect foresight. Equation (1) implies that mines do not engage in intertemporal arbitrage by stockpiling. They do not extract Rare Earths and store them above the ground anticipating future price increases. This is a slight contradiction to the assumption of perfect foresight. As will turn out in the numerical results later, falling Rare Earths prices over much of $T$ limit the incentive to stockpile and thus the importance of this assumption. $\delta$ is the discount factor which is assumed to be $7 \%$ for all mines.

$$
\begin{aligned}
\max _{t}^{m n, \Delta \mathbf{C a p}_{t}^{m n}} \Pi^{m n} & = \\
& \sum_{t=0}^{T}\left[\left(\sum_{r e o} \alpha^{r e o, m n} \cdot \mathbf{p} \mathbf{M} \mathbf{N}_{r, t}^{r e o}+\mu^{m n}-c^{m n}\right) \mathbf{e x}_{t}^{m n}-\right. \\
& \left.c I n v^{m n}\left(\boldsymbol{\Delta} \mathbf{C a p}_{0}^{m n}, \ldots, \mathbf{\Delta} \mathbf{C a p}_{t}^{m n}, \ldots, \mathbf{\Delta} \mathbf{C a p}_{T}^{m n}\right)\right] \delta^{-t}
\end{aligned}
$$

The mines have to comply with two restrictions. Firstly, a mine must not extract more than the known exogenous resource stock $R^{m n}$. This strict approach of restricting extraction resembles Hotelling (1931). Allowing for endogenous investment in exploring and developing further deposits would increase the validity of the model's results (Adelman, 1990). Neglecting endogenous increases in resource stocks does not bias the model's results, however, due to the large size of deposits already considered in the database for Rare Earths and the mid-term perspective of the simulations.

$$
R^{m n} \geq \sum_{t=0}^{T} e x_{t}^{m n}
$$

Secondly, physical capacities limit the extraction in each year $t$. Equation (3) specifies the capacity constraint. The initial capacity is denoted $c a p 0^{m n}$. Opening up a Rare Earth mine can take ten years and more. This is reflected by the mine-specific lag between the investment and the commencement of production lagInv $v^{m n}$. Ramping up a mine to full capacity takes some time as well. Therefore, capacity is reduced by $50 \%$ in the first year 
in which investment comes into effect.

$$
c a p 0^{m n}+\sum_{t t=1}^{t-\left(\operatorname{lagInv}^{m n}-1\right)} \Delta \mathbf{C a p}_{t t}^{m n}+0.5 \cdot \Delta \mathbf{C a p}_{t-\text { laginv }^{m n}}^{m n} \geq \mathbf{e x}_{t}^{m n} \forall t
$$

Mines maximize their profits according to equation (1) under the constraints characterized by (2) and (3). Formulating the optimization problem as a mixed complementarity problem reflects some mines do not invest and thus do not enter the market. The zero profit condition in equation (4) determines the mines' extraction. The operator $\perp$ signifies the complementarity between an inequality and the associated variable. Discounted per unit profits have to outweigh the shadow prices of both the resources constraint $\lambda \mathbf{R}^{m n}$ and the capacity constraint $\lambda \mathbf{C a p}_{t}^{m n}$ for production to take place.

$$
\begin{gathered}
\lambda \mathbf{R}^{m n}+\lambda \mathbf{C a p}_{t}^{m n} \geq\left(\sum_{r e o} \alpha^{r e o, m n} \cdot \mathbf{p} \mathbf{M} \mathbf{N}_{r, t}^{r e o}+\mu^{m n}-c^{m n}\right) \delta^{-t} \perp \mathbf{e x}_{t}^{m n} \geq 0 \\
\forall m n, t
\end{gathered}
$$

The shadow price of the resources constraint is determined by equation (5).

$$
R^{m n} \geq \sum_{t=0}^{T} \mathbf{e x}_{t}^{m n} \perp \lambda \mathbf{R}^{m n} \geq 0 \quad \forall m n
$$

Equation (6) is the shadow price of the capacity constraint.

$$
c a p 0^{m n}+\sum_{t t=1}^{t t-\left(\operatorname{lagInv} v^{m n}-1\right)} \Delta \mathbf{C a p}_{t}^{m n}+0.5 \cdot \Delta \mathbf{C a p}_{t-l a g I n v^{m n}}^{m n} \geq \mathbf{e x}_{t}^{m n} \perp \lambda \mathbf{C a p}_{t}^{m n} \geq 0
$$

$\forall m n, t$

The investment cost function $c \operatorname{Inv} v^{m n}$ remains to be specified. Partial equilibrium models applied on metal markets so far were static. The theoretical literature indicates, however, that capacity constraints and investment costs are important for modeling the behavior of extractive sectors correctly (Hartwick et al., 1985; Cairns, 2001; Holland, 2003). That is certainly the case for a dynamic sector such as Rare Earth mining.

Some determinants of mine capacities can not be depicted explicitly in the model. These include in particular capital constrains for highly risky investments such as Rare Earths' mining. Therefore, I chose a form-follows-function approach by defining an investment costs function that reliably yields realistic investment behavior and capacities. The investment cost function has to replicate the following stylized facts. 1) Marginal 
costs if increasing capacity must be greater than zero already at zero capacity to avoid unrealistically small investments. 2) $c \operatorname{Inv} v^{m n}$ has to be convex to prevent unrealistically large capacities. 3) Today's investment has to increase investment costs in the future $\left(\frac{\partial c I n v_{t t}^{m n}}{\partial \boldsymbol{\Delta} \mathbf{C a p}_{t}^{m n}}>0 \forall t t>t\right)$. Otherwise, mines could spread investment and increase their capacities in small steps to circumvent the convexity of investment costs. Such investment behavior would be unrealistic, however. 4) If capacities equal those announced by the mining company, investment costs should match the announced ones.

The investment cost function (7) is used in the METRO model. $c I \tilde{v}^{m n}$ and $c a \tilde{p}^{m n}$ denote capacities and corresponding investment costs announced by the mining firm. $c a p 0^{m n}$ is the initial capacity of mine $m n$ in 2013. $\xi$ and $\varphi$ are parameters used to calibrate the investment costs. As can be easily verified, the investment cost function (7) fulfills all four criteria.

$$
\begin{aligned}
& c \operatorname{Inv} v_{t}^{m n}\left(\boldsymbol{\Delta} \mathbf{C a p}_{0}^{m n}, \ldots, \Delta \mathbf{C a p}_{T}^{m n}\right)= \\
& \boldsymbol{\Delta} \mathbf{C a p}_{t}^{m n}\left[\xi \frac{c I n \tilde{v}^{m n}}{c a \tilde{p}^{m n}}+(1-\xi) \frac{c \operatorname{Inv} \tilde{v}^{m n}}{c a \tilde{p}^{m n}}\left(\frac{c a p 0^{m n}+\sum_{t t \leq t} \mathbf{\Delta} \mathbf{C a p}_{t t}^{m n}}{c a \tilde{p}^{m n}}\right)^{\varphi}\right] \\
& 0<\xi<1,1<\varphi<\infty
\end{aligned}
$$

The first term within the square brackets in equation (7) is the constant marginal cost part. The second term is convex $(\varphi>1)$. It is increasing in investment in all $t t \leq t$. The parameter $\xi$ denotes the weighting between the linear and the convex part. $\varphi$ determines the degree of convexity.

Equation (8) characterizes the zero profit conditions with respect to investment. The gains from relaxing the capacity constraint have to outweigh the marginal costs of investment. Mines have to take into account the effects of investing in $t$ on costs in $t t>t$. Building up capacities today makes it more costly to further expand them in the future (equation 10).

$$
\begin{aligned}
\frac{\partial c \operatorname{Inv} v_{t}^{m n}}{\partial \boldsymbol{\Delta} \mathbf{C a p}_{t}^{m n}} \delta^{-t} & +\sum_{t t>t} \frac{\partial c \operatorname{Inv} v_{t t}^{m n}}{\partial \mathbf{\Delta} \mathbf{C a p}_{t}^{m n}} \delta^{-t t} \geq \\
& \sum_{t t>t+l a g I n v^{m n}} \boldsymbol{\Delta} \mathbf{C a p}_{t t}^{m n}+0.5 \cdot \boldsymbol{\Delta} \mathbf{C a p}_{t-l a g i n v^{m n}}^{m n} \perp \boldsymbol{\Delta} \mathbf{C a p}_{t}^{m n} \geq 0 \forall m n, t
\end{aligned}
$$


with

$$
\begin{aligned}
\frac{\partial c \operatorname{Inv} v_{t}^{m n}}{\partial \mathbf{\Delta} \operatorname{Cap}_{t}^{m n}} & = \\
& \frac{c \operatorname{In\tilde {v}} \tilde{\tilde{p}}^{m n}}{c a \tilde{p}^{m n}}\left(\xi+(1-\xi)\left[\left(\frac{c a p 0^{m n}+\sum_{t t \leq t} \mathbf{\Delta} \mathbf{C a p}_{t t}^{m n}}{c a \tilde{p}^{m n}}\right)^{\varphi}+\right.\right. \\
& \left.\left.\frac{i n v_{t}^{m n} \cdot \varphi}{c a \tilde{p}^{m n}}\left(\frac{c a p 0^{m n}+\sum_{t t \leq t} \boldsymbol{\Delta} \mathbf{C a p}_{t t}^{m n}}{c a \tilde{p}^{m n}}\right)^{\varphi-1}\right]\right)
\end{aligned}
$$

and

$$
\frac{\partial c \operatorname{Inv} v_{t t}^{m n}}{\partial \boldsymbol{\Delta} \mathbf{C a p}_{t}^{m n}}=(1-\xi) \frac{c I n \tilde{v}^{m n}}{c a \tilde{p}^{m n}} \frac{i n v_{t t}^{m n} \cdot \varphi}{c a \tilde{p}^{m n}}\left(\frac{c a p 0^{m n}+\sum_{t t t \leq t t} \mathbf{\Delta} \mathbf{C a p}_{t t t}^{m n}}{c a \tilde{p}^{m n}}\right)^{\varphi-1}
$$

\subsection{Trade Sector}

Let us assume that Rare Earths are traded by sectors whose behavior can be modeled by a representative price-taking firm in each region. They are implemented to display trade flows of Rare Earths, both within and between regions.

The trade firm in $r$ buys $\mathbf{i} \mathbf{T r}_{s, r, t}^{r e o, m n}$ tons of Rare Earth reo at mine $m n$ in country $s$. The index $s$ signifies the regions of the model (like $r$ ). The trade sectors also purchase recycled Rare Earths $\mathbf{i R e c}_{r, t}^{r e o}$ from domestic recycling firms. This implies that secondary raw materials are not traded internationally. Primary and secondary raw materials are assumed to be perfect substitutes. The representative firm sells the metals to domestic industries.

The trade sectors receive the purchaser price of $\mathbf{p} \mathbf{D}_{r, t}^{r e o}$. They pay the producer price $\mathbf{p M N}_{s, t}^{r e o}$ for inputs of virgin metals from region $s$, plus the ad-valorem tariff $\tau_{s, r}$, if relevant. Transport costs are neglected, but could be implemented for metals with a lower valueto-weight ratio for which they are more important (Lanz et al., 2013). Prices for recycled Rare Earths are $\mathbf{p} \mathbf{R e c}_{r, t}^{r e o}$.

Trade firms maximize their profits according to equation (11). They do not invest in capacities or stockpile metals. Therefore, profits can be maximized separately in each year $t . \zeta(m n, s)$ is a boolean parameter which is true if mine $m n$ is located in region $s$. 
It is needed to avoid double counting.

$$
\begin{aligned}
& \max _{\mathbf{i}_{\operatorname{Tr}_{s, r, t}^{r e o, m n}, \mathbf{i R e c} \mathbf{R e}_{r, t}^{r e o}} \Pi_{r, t}^{t r}=} \sum_{r e o}\left[\left(\sum_{s} \sum_{\{m n \mid \zeta(m n, s)\}} \mathbf{i T r}_{s, r, t}^{r e o, m n}+\mathbf{i} \mathbf{R e c}_{r, t}^{r e o}\right) \mathbf{p} \mathbf{D}_{r, t}^{r e o}-\right. \\
& \left.\sum_{s}\left(\sum_{\{m n \mid \zeta(m n, s)\}} \mathbf{i T r}_{s, r, t}^{r e o, m n} \cdot \mathbf{p} \mathbf{M N}_{s, t}^{r e o}\left(1+\tau_{s, r}\right)\right)-\mathbf{i} \mathbf{R e c}_{r, t}^{r e o} \cdot \mathbf{p R e c} \mathbf{R e}_{r, t}^{r e o}\right]
\end{aligned}
$$

Quotas limiting exports from China are known to be an important driver of Rare Earth prices. I introduce two separate quotas, one for Light $\left(Q_{C n, t}^{l r e o}\right)$ and one for Heavy Rare Earths $\left(Q_{C n, t}^{h r e o}\right)$. They constrain the exports of Rare Earths from China to all other regions according to the equations (12) and (13).

$$
\begin{aligned}
& \sum_{r e o \in l r e o} \sum_{r \neq C n} \sum_{\{m n \mid \zeta(m n, C n)\}} \mathbf{i T r}_{C n, r, t}^{r e o, m n} \leq Q_{C n, t}^{l r e o} \forall t \\
& \sum_{r e o \in h r e o} \sum_{r \neq C n} \sum_{\{m n \mid \zeta(m n, C n)\}} \mathbf{i T r}_{C n, r, t}^{r e e, m n} \leq Q_{C n, t}^{h r e o} \forall t
\end{aligned}
$$

Maximizing the trading firms' profits yields the zero profit conditions determining inputs of primary and secondary raw materials. Equation (14) characterizes the first order conditions for inputs from all mines which are not subject to Chinese export quotas. That is inputs from all mines outside China and inputs from domestic mines.

$$
\begin{array}{r}
0 \geq \mathbf{p} \mathbf{D}_{r, t}^{r e o}-\mathbf{p M N}_{s, t}^{r e o}\left(1+\tau_{s, r}\right) \perp \mathbf{i} \mathbf{T r}_{s, r, t}^{r e o, m n} \geq 0 \\
\forall r e o,\{r, s \mid s \neq C n \vee r=s\}, t
\end{array}
$$

Equation (15) displays the first order conditions for inputs from Chinese mines into nonChinese trading sectors. Profits must not only compensate the purchaser price plus tariffs, but also the shadow prices of the export quotas, $\lambda \mathbf{Q}_{C n, t}^{\text {lreo }}$ or $\lambda \mathbf{Q}_{C n, t}^{\text {hreo }}$. Export restrictions between China and all other regions and the absence of other trade costs implies the existence of two prices. One in China and one in all other regions.

$$
\mathbf{p D}_{r, t}^{r e o}-\mathbf{p M N}_{C n, t}^{r e o}\left(1+\tau_{C n, r}\right) \leq \begin{cases}\lambda \mathbf{Q}_{C n, t}^{\text {lreo }}, \text { reo } \in \text { lreo } & \\ \lambda \mathbf{Q}_{C n, t}^{\text {hreo }}, \text { reo } \in \text { hreo } & \\ & \forall \text { i } \operatorname{Tr}_{C n, r, t}^{r e o, m n} \geq 0 \\ & \forall \text { reo }, \quad \neq n, t\end{cases}
$$


Equation (16) shows the zero profit conditions for inputs of recycled Rare Earths.

$$
0 \geq \mathbf{p} \mathbf{D}_{r, t}^{r e o}-\mathbf{p R e c}_{r, t}^{r e o} \perp \mathbf{i R e c}_{r, t}^{r e o} \geq 0 \quad \forall r e o, r, t
$$

The shadow prices of the quotas for Light $\left(\lambda \mathbf{Q}_{C n, t}^{\text {lreo }}\right)$ and Heavy Rare Earths $\left(\lambda \mathbf{Q}_{C n, t}^{\text {hreo }}\right)$ are determined by equations (17) and (18), respectively.

$$
\begin{aligned}
& Q_{C n, t}^{l r e o} \geq \sum_{r e o \in l r e o} \sum_{r \neq C n} \sum_{\{m n \mid \zeta(m n, C n)\}} \mathbf{i T r}_{C n, r, t}^{r e o, m n} \perp \lambda \mathbf{Q}_{C n, t}^{l r e o} \geq 0 \forall r e o, t \\
& Q_{C n, t}^{h r e o} \geq \sum_{r e o \in h r e o} \sum_{r \neq C n} \sum_{\{m n \mid \zeta(m n, C n)\}} \mathbf{i T r}_{C n, r, t}^{r e o, m n} \perp \lambda \mathbf{Q}_{C n, t}^{h r e o} \geq 0 \forall r e o, t
\end{aligned}
$$

\subsection{Demand}

Demand for Rare Earths is derived from the demand for goods containing the metals. Tracing them trough their value chains is prohibitively costly given their diverse and specialized applications. Demand is therefore modeled by demand functions representing industries using Rare Earths. Seven applications app are considered. Catalysts, glass, metallurgy (including batteries), phosphors, magnets, ceramics and other applications. Demand for Rare Earth reo in application app is determined by

$$
\mathbf{D}_{r, t}^{r e o, a p p}=\Delta_{r, t}^{r e o, a p p}\left(\frac{\mathbf{p} \mathbf{D}_{r, t}^{r e o}}{p \tilde{D}_{r, t}^{r e o}}\right)^{\epsilon_{t}} \forall r e o, a p p, r, t .
$$

The parameter $\Delta_{r, t}^{r e o, a p p}$ is the prognosticated demand. $p \tilde{D}_{r, t}^{r e o}$ and $\mathbf{p} \mathbf{D}_{r, t}^{r e o}$ are the expected and the endogenous consumer prices, respectively. The price elasticity of demand is denoted $\epsilon_{t}$ and assumed identical in all applications and regions.

\subsection{Recycling}

A model depicting metal markets needs to consider recycling. While Rare Earths can be recycled technically, prohibitive costs have precluded it on an industrial scale up until now (UNEP, 2011; Schüler et al., 2011). This implies a lack of historical data to parameterize recycling costs. The following approach was chosen to resolve this problem. A recycling module is integrated into the METRO model, which is usually switched off. Implications of introducing recycling can be derived by assuming a level of recycling costs and solving the model. The recycling sector is modeled as follows. 
A representative firm in each country recycles of Rare Earths. They maximize their profits according to equation (20), taking prices for their outputs $\mathbf{p R e c} \mathbf{C}_{r, t}^{r e o}$ as given. Each unit $\operatorname{Rec}_{r, t}^{a p p}$ from application app contains a share of $\beta^{r e o, a p p}$ of Rare Earth reo. The per-unit revenue is a weighted sum of prices for recycled Rare Earths. The weights are $\beta^{r e o, a p p}$. The recycling firms incur constant marginal costs $c R e c_{r, t}^{a p p}$.

$$
\max _{\operatorname{Rec}_{r, t}^{a p p}} \Pi_{a p p, r, t}^{r e c}=\left[\sum_{r e o} \beta^{r e o, a p p} \cdot \mathbf{p} \mathbf{R e c}_{r, t}^{r e o}-c \operatorname{Rec} c_{r, t}^{a p p}\right] \mathbf{R e c}_{r, t}^{a p p}
$$

The amount of recycled Rare Earths must not exceed the quantities available for recycling. Equation (21) represents this constraint. For the sake of simplicity, a constant lifetime of products lagRec ${ }^{a p p}$ is assumed. Metals available for recycling in $t$ are determined by the demand in $t-l a g R e c^{a p p}$.

$$
\frac{\operatorname{Rec}_{r, t}^{a p p}}{\sum_{r e o} \mathbf{D}_{r, t-l a g R e c}^{r e o, a p p}} \leq 1
$$

Maximizing the recycling firms' profits according to equation (20) yields the following zero profit conditions. The variable $\lambda \mathbf{R e c R} \mathbf{a}_{r, t}^{a p p}$ represents the shadow price of the constraint on the recycling rate.

$$
\lambda \mathbf{R e c R a}_{r, t}^{a p p} \geq \sum_{r e o} \beta^{r e o, a p p} \cdot \mathbf{p R e c}_{r, t}^{r e o}-c \operatorname{Rec} c_{r, t}^{a p p} \quad \perp \mathbf{R e c}_{r, t}^{a p p} \geq 0 \forall a p p, r
$$

The shadow price of constraint (21) is determined by equation (23).

$$
\sum_{r e o} \mathbf{D}_{r,-l a g R e c c^{a p p}}^{r e o, a p p} \geq \mathbf{R e c}_{r, t}^{a p p} \quad \perp \lambda \mathbf{R e c R} \mathbf{a}_{r, t}^{a p p} \geq 0 \quad \forall a p p, r
$$

\subsection{Market Clearing Conditions}

Price levels are determined by the market clearing conditions. In its application for Rare Earths, the METRO model has three types of prices to be determined. The producer price at the mines $\mathbf{p} \mathbf{M} \mathbf{N}_{r, t}^{r e o}$, the purchasers price faced by demand sectors $\mathbf{p} \mathbf{D}_{r, t}^{r e o}$ and the price of recycled Rare Earths $\mathbf{p R e c} \mathbf{R e o}_{r, t}^{r e o}$.

Equation (24) shows the market clearing condition for the mines. The left-hand side of the inequality is the output of Rare Earth $m n$ all mines in region $r$. The right-hand 
side is the demand by trading firms in all regions $s$ for reo in region $r$.

$$
\begin{array}{r}
\sum_{\{m n \mid \zeta(m n, r)\}} \alpha^{m n, r e o} \cdot \mathbf{e x}_{r, t}^{m n} \geq \sum_{s} \sum_{\{m n \mid \zeta(m n, r)\}} \mathbf{i T r}_{r, s, t}^{r e o, m n} \perp \mathbf{p M} \mathbf{N}_{s, t}^{r e o} \geq 0 \\
\forall r e o, r, t
\end{array}
$$

Market clearing conditions for the demand are shown in equation (25).

$$
\sum_{s} \sum_{\{m n \mid \zeta(m n, s)\}} \mathbf{i} \operatorname{Tr}_{s, r, t}^{r e o, m n} \geq \sum_{a p p} \mathbf{D}_{r, t}^{r e o, a p p} \perp \mathbf{p D}_{r, t}^{r e o} \geq 0 \quad \forall r e o, r, t
$$

Equation (26) determines the prices for recycled Rare Earths.

$$
\sum_{a p p} \beta^{r e o, a p p} \cdot \mathbf{R e c}_{r, t}^{a p p} \geq \mathbf{i} \operatorname{Rec}_{r, t}^{r e o} \perp \mathbf{p R e c}_{r, t}^{r e o} \geq 0 \quad \forall r e o, r, t
$$

\section{Data}

\subsection{Mining Sector}

A number of mine-specific parameters are needed to parameterize the model. Most notably data on resource stocks, shares of individual Rare Earths, by-products, as well as cost data and announced capacities. Readily available data to calibrate the model does not exist, which is why I compiled a novel dataset. The approach chosen differs between Chinese mines, non-Chinese fringe producers already active prior to 2012, and new non-Chinese suppliers.

Compiling a dataset for Chinese Rare Earth mines involves two problems. Firstly, reliable data on those mines is not available. Secondly, the assumption of small profitmaximizing firms is not plausible, in particular for the large state owned mines. Thus, all Chinese mines are aggregated into one firm which is assumed to produce an exogenous quantity of Rare Earths every year $t$. This reflects the fact that the Chinese government exhibits tight control over its domestic Rare Earths production and that it pursues goals beyond mere profit maximization. Recently announced plans to create a more concentrated mining sector with greater state influence (SCIO, 2012) and studies emphasizing China's diverse policy goals (Wübbeke, 2013; Pothen and Fink, 2013) confirm this assumption.

A number of small fringe producers in Brazil, India and Malaysia were active before 2012 (U.S. Geological Survey, 2012b). These firms are aggregated into one mine. Their output is assumed to remain constant. 
Until 2012, there was basically no Rare Earth supply outside Chinese other than the above mentioned fringe producers. New non-Chinese firms are aiming, however, at setting up a Rare Earths mine. These projects are usually run by small junior mining companies listed at stock exchanges in either the US, Canada or Australia. I exploited this fact to compile a dataset on (potential) Rare Earth mines to calibrate the model.

Initially, the relevant ones out of the 400 mining projects planning to enter the market (Hatch, 2012a) had to be identified. Technology Metals Research (2012) lists all Rare Earth projects which at least prepared resource estimates based on internationally accepted standards in 2012. The dataset is further restricted to projects for which cost data was available, because cost estimates are required for calibration. Many of the projects within the dataset plan to commence production only by 2017 or 2018 . Thus, excluding less advanced projects is not likely to bias the model's results. 17 mining projects satisfy the above criteria. ${ }^{2}$

Data for each mine is taken from feasibility studies published and filed at the stock exchange by its owner. Feasibility studies are prepared to analyze if a project is expected to be both technically feasible and economically profitable. They include comprehensive geological data, resource estimations, construction plans for the mine, engineering cost estimates, and some market prospective (Rudenno, 2009). Usually, multiple feasibility studies are compiled until a mine commences production, with an increasing degree of reliability. Reviews of feasibility studies indicate that they tend to estimate costs and opening dates optimistically (Mackenzie and Cusworth, 2007; Noort and Adams, 2006). This is, however, a problem common to large scale construction projects in general (e.g. Assaf and Al-Hejji, 2006).

All data is derived from feasibility studies published no later than the 31st of July 2012. If more than one feasibility study is available, the most recent one is used. If more than one mine plan is available, the one recommended by the firm is used. If multiple resource estimates are presented, the one underlying the mine plan is used, if possible. If the announced capacity $c a \tilde{p}^{m n}$ was not expressed in tons of Rare Earth Oxides, data was converted using ore grades and recovery rates. The announced year of

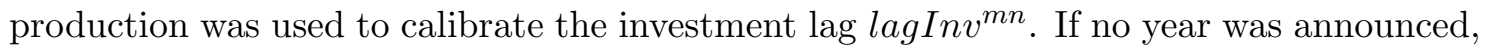
2018 was assumed. Cost data was converted into constant US\$. Some mines do not aim at producing Rare Earth Oxides but intermediate products. Extraction costs were

\footnotetext{
${ }^{2}$ Two other projects are likely to commence production in the near future. The Dong Pao Project in Viet Nam and the Orissa Project in India. Both are undertaken by Japanese Industry. Only scattered information about those is available. Hence, they are excluded from the dataset.
} 
adjusted to reflect additional costs of processing those into Rare Earth Oxides. Reserves for contingencies, which are presented in the feasibility studies and usually account for about $15 \%$ of overall investment costs, of are included in the investment costs reflecting the tendency to underestimate investment costs.

The mining projects included in the database exhibit great diversity. Most of them are located in the OECD. Four are planned in the US, six in Canada, three in Australia and one in Sweden. Two mines are planned in Greenland ${ }^{3}$ and one in South Africa. The ore grades, i.e. the share of metals contained in a unit of ore, vary widely between $9.8 \%$ and $0.06 \%$.

\begin{tabular}{|c|c|c|c|c|}
\hline & \multirow[b]{2}{*}{$\begin{array}{l}\text { Resource } \\
\text { (tons of REO) }\end{array}$} & \multicolumn{3}{|c|}{ Mine Data Descriptive Statistics } \\
\hline & & $\begin{array}{l}\text { Planned capacity } \\
\text { (tpa) }\end{array}$ & $\begin{array}{l}\text { Investment costs } \\
(\mathrm{US} \$ \text { per tpa) }\end{array}$ & $\begin{array}{r}\text { Operational costs } \\
(\mathrm{US} \$ \text { per } \mathrm{kg})\end{array}$ \\
\hline Min & 70,912 & 4,008 & 19,961 & 2.90 \\
\hline Max & $5,331,400$ & 40,800 & 295,510 & 68.06 \\
\hline Av. & 773,705 & 13,130 & 85,402 & 28.95 \\
\hline
\end{tabular}

Table 2: Descriptive statistics of non-Chinese mines

Table 2 presents some descriptive statistics of the dataset. The project with the smallest resource stock only encompasses about 70,000 tons of REO, the largest one contains more than 5 million tons. Comparing these numbers with an annual consumption of 110,000 to 125,000 tons per year indicates that exhaustion of Rare Earths is not an urgent problem.

Planned capacities range from 4,000 tpa to 40,000 tpa REO with an average of about 13,000 tpa. Investment costs in Rare Earth mining are high, even by the standards of the mining sector. Costs range from 20,000 to almost 300,000 US $\$$ per ton of capacity. Processing facilities usually make up for a large share of investment costs. Extraction costs also vary strongly, from about 3 US\$ to 70 US\$ per kg of Rare Earth Oxides. Cost data in table 2 has to be interpreted with care, however. Costs of extracting and processing by-products are allocated to Rare Earth extraction. This overestimates the costs for mines planning to sell by-products as well.

Mines in the dataset exhibit considerable variation with respect to the year in which they plan to commence production. Figure 5 presents the number of mines which an-

\footnotetext{
${ }^{3}$ Greenland is neither member of the EU, nor of the OECD.
} 


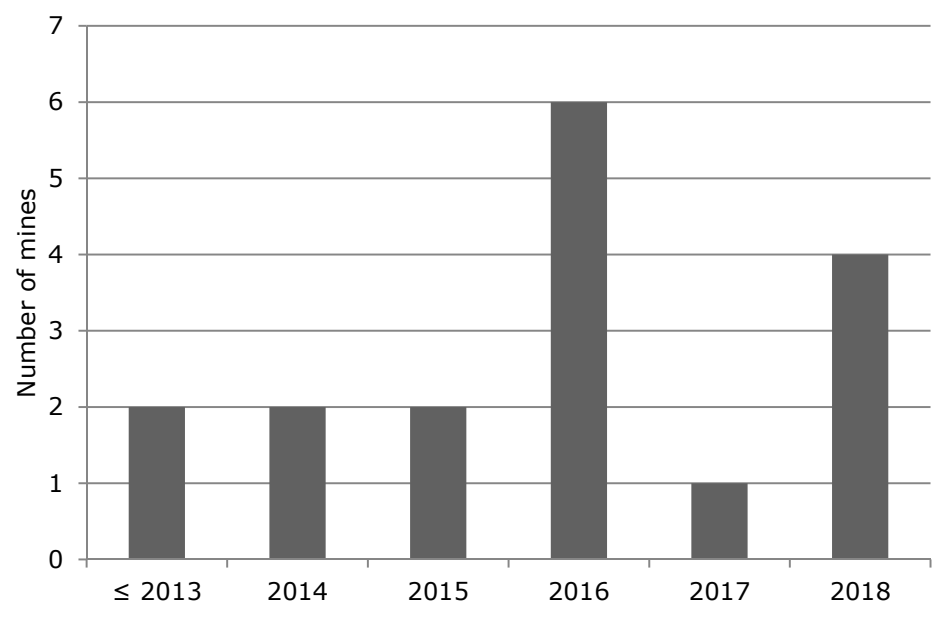

Figure 5: Number of mines planning to commence production per year

nounced to start producing Rare Earths per year. While two mines already entered the market in 2013, others only expect to produce by 2018. The year in which most mines plan to commence operation is 2016 .

The investment cost function is parameterized by assuming $\xi=0.4$ and $\varphi=10$. In the baseline simulations, the difference between proposed capacities and those projected by the model is $11.7 \%$ which can be considered sufficiently realistic. Sensitivity checks reveal that results are robust to variations in $\xi$ and $\varphi$.

\subsection{Demand}

Demand for Rare Earths is calibrated according to prognoses by Kingsnorth (2012) which are displayed in table 3. $\Delta_{r, t}^{r e o, a p p}$ is parameterized per application app. Applications differ with respect to the Rare Earths employed in them. Information about which Rare Earths are used in which applications is derived from U.S. Geological Survey (2011) and held constant. ${ }^{4}$

Demand for metals is derived from the demand for products containing them. Their prices often account only for a minor share of the final products' costs, thus metal demand reacts inelastically on price changes in the short run. Agostini (2006) presents estimates for the price elasticity of demand for copper ranging from -0.19 to -0.47 . In the case of aluminum, Fisher and Owen (1981) estimate short-run elasticities of -0.25 in long-run

\footnotetext{
${ }^{4}$ The only exception is the use of Cerium in the application Other. The demand for cerium is increased additionally to reflect the introduction of waste water cleaning technologies heavily relying on Cerium (Kingsnorth, 2012).
} 


\begin{tabular}{lll} 
Application & $\begin{array}{l}\text { Demand } 2011 \\
\text { tpa }\end{array}$ & $\begin{array}{l}\text { Projection } 2016 \\
\text { tpa }\end{array}$ \\
\hline Catalysts & 20,000 & 25,000 \\
Glass & 8,000 & 10,000 \\
Polishing & 14,000 & 18,000 \\
Metal alloys & 21,000 & 30,000 \\
Magnets & 21,000 & 36,000 \\
Phosphors & 8,000 & 12,000 \\
Ceramics & 7,000 & 10,000 \\
Other & 6,000 & 19,000 \\
Total & 105,000 & 160,000 \\
& & \\
\hline
\end{tabular}

Table 3: Demand projections

Source: Kingsnorth (2012)

ones of -0.3. Gupta (1982) finds large variation in the demand price elasticity for Zinc. The numbers vary between -0.005 and -0.78 . In their model of steel sectors, Demailly and Quirion (2008) and Gielen and Moriguchi (2002) assume demand elasticities of -0.3 and -0.2 , respectively. Here, the price elasticity of demand is assumed to be $\epsilon_{t}=-0.3$ for all applications in the model. Elasticities increase to a value of $\epsilon_{t}=-0.5$ in 2020 to account for growing flexibility in the long run.

\subsection{Prices and Trade Restrictions}

All prices for Rare Earths are based on data from asianmetal.com. Domestic prices for China and foreign prices (FOB China) are available for most Rare Earth Oxides. The arithmetic mean of daily data is used to compute annual averages.

Chinese export tariffs for Rare Earths are taken from Tse (2011). Data on recent export quotas is available in Hatch (2012b, 2013a). Note that setting export restrictions according to the official Chinese numbers found in Hatch $(2012 b, 2013 a)$ assumes no smuggling of Rare Earths to take place in the future. This reflects both the increasing efforts of the Chinese government to put a kybosh on illegal exports and the lack of data about the costs of smuggling. 


\section{Simulation Results}

\subsection{Baseline}

The METRO model is applied to assess key developments of supply, demand, and prices of Rare Earths until 2020. This section presents the results based on the following assumptions. Export quotas and tariffs remain unchanged at the levels of 2013. Due to a lack of data, export barriers implied by the allocation of export licenses and illegal exports are not considered in the model. Chinese production is assumed to be exogenously determined and increases to 150,000 tons in 2018. Recycling costs are prohibitive.

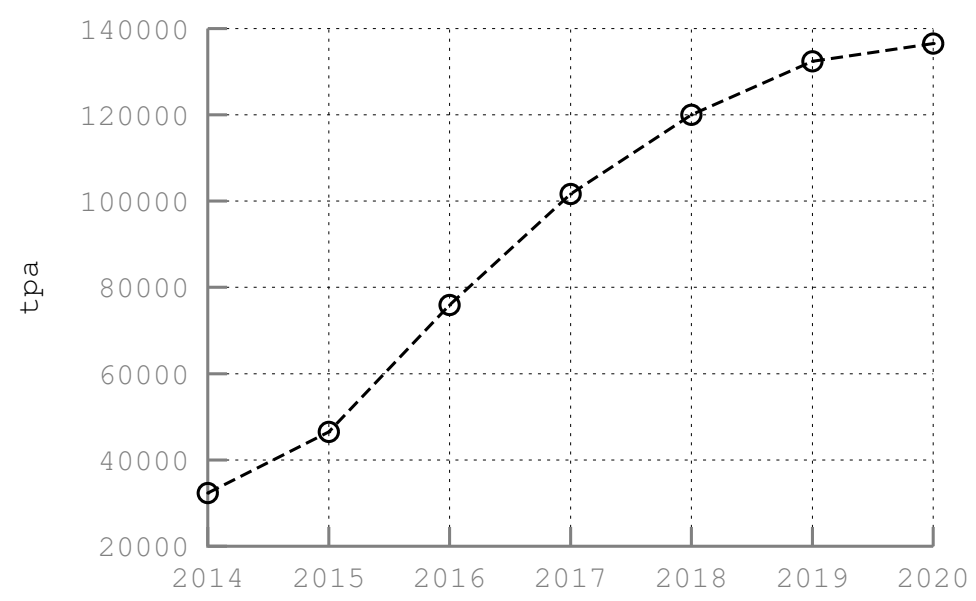

Figure 6: Non-Chinese mining capacities in tpa.

The results reveal that non-Chinese suppliers expand their capacities considerably until 2020. Figure 6 shows the capacities of all mines outside China in tpa. They more than quadruple from about 32,000 in 2014 tpa to 137,000 tpa in 2020. Capacities increase particularly from 2015 to 2017 . Almost 50\% of Rare Earths are mined outside China by the end of the decade.

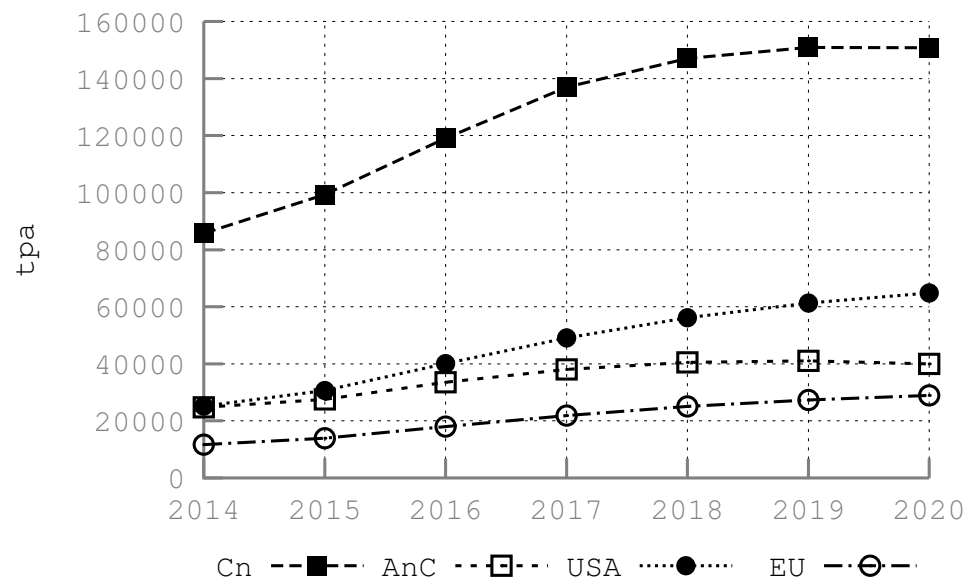

Figure 7: Demand for Rare Earths by region in tpa. 
Figure 7 displays the demand for Rare Earths by region $r$ in tpa. All regions increase their consumption, both due to exogenous increases in $\Delta_{r, t}^{r e o, a p p}$ and due to falling prices of Rare Earths, in particular outside China. By 2020, worldwide demand for Rare Earths increases to 285,000 tpa. This is higher than the long term prognoses by Kingsnorth (2013) who expects demand to rise to 240,000 tpa and supply to increase up to 280,000 tpa. The United States increase their share of consumption, also compared to the EU and the rest of Asia. Recall that prices outside China are identical and do not explain different demand growth rates in the US, the EU and the rest of Asia. They can be ascribed to the data. The USA have greater shares in industries for which Kingsnorth (2012) estimates high growth rates.



Figure 8: Prices of LREO and HREO in China and the rest of the world in US\$ per kg.

Prices for Light Rare Earth Oxides (LREO) and Heavy Rare Earth Oxides (HREO) in China $(\mathrm{Cn})$ and in the rest of the world (RoW) are presented in figure 8. The results underline the importance of distinguishing between Light and Heavy Rare Earths. For both LREO and HREO, falling prices are expected. The speed of the decline differs by type of Rare Earth, however.

Prices of HREO diverge strongly between the two regions, in particular until 2015. While a kg of Heavy Rare Earth Oxides is expected to cost around 100 US\$ in China, its price is about 250 US $\$$ in other countries. Prices in the rest of the world start to decline in 2016. In 2020, both Chinese and non-Chinese prices are around 90 US $\$$. LREO prices are lower. In the rest of the world, they are above 30 US\$ per kg until 2015. Chinese prices are below 26 US $\$$. They fall from 2016 onwards, too.

The falling prices, in particular outside China, can be explained by market entry. As figure 6 shows, non-Chinese suppliers expand their capacities strongly from 2016 to 2018. Consequently, prices drop due to boosting supply and they drop more strongly outside 
China because new suppliers are not affected by Chinese trade restrictions. Market entry occurs differently for Light and Heavy Rare Earths. Mining projects which are able to enter the market until 2016 are rich in Light Rare Earths. Mines with deposits rich in Heavy Rare Earths have longer lags lagInv ${ }^{m n}$. Capacities for Heavy Rare Earths exceed 1,000 tpa only in 2016. Therefore, price differences between China and the rest of the world are more persistent for HREO.

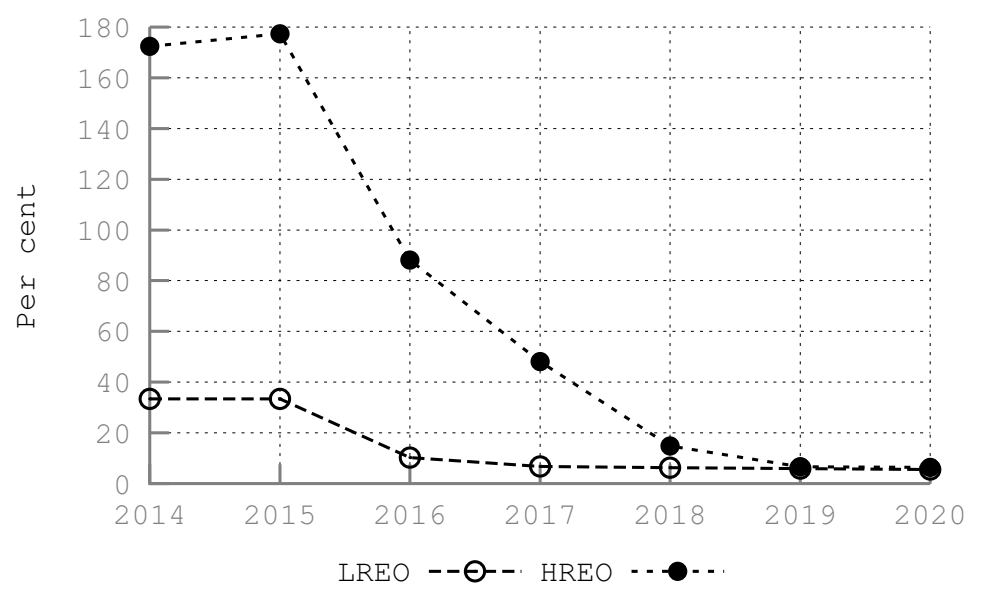

Figure 9: Prices of LREO and HREO relative to China in per cent.

Figure 9 shows the difference between non-Chinese and Chinese prices in per cent, both for LREO and HREO. The pattern is similar to that in figure 8. Price differences are larger and more persistent for Heavy than for Light Rare Earths. In 2014 and 2015, LREO are around $30 \%$ more expensive in the rest of the world than in China. HREO prices are about $170 \%$ higher. Both numbers decline from 2016 onwards. Only by 2019, the price difference of HREO corresponds to that of LREO (around 6\%).

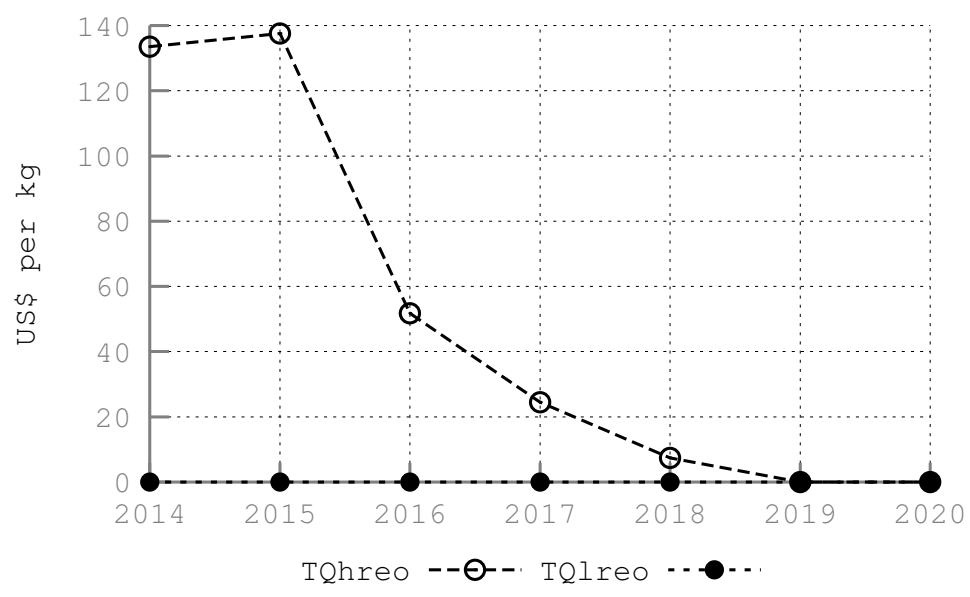

Figure 10: Shadow price of export quotas in $\mathrm{kg}$ per US\$.

Quotas are among the most important instruments China uses to restrict exports of Rare Earths. Figure 10 presents the shadow prices implied by the export quotas on LREO 
and HREO in US\$ per kg. TQhreo denotes the shadow price of the quota on Heavy Rare Earths, TQlreo the one on Light Rare Earths. The quota on LREO is non-binding already in 2014 and the associated shadow price remains zero until 2020. Maintaining the quota on HREO implies a shadow prices above 130 US $\$$ per kg in 2014 and 2015. It drops to 52 US\$ in 2016. The export quota on Heavy Rare Earths becomes non-binding by 2019 only. These numbers reflect a greater dependency on Chinese supply for Heavy Rare Earths.

\begin{tabular}{ll}
\hline \multicolumn{2}{c}{ Welfare Changes } \\
in the Status-quo Scenario \\
\multicolumn{1}{l}{ Region } & $\Delta W_{r}$ \\
\hline & \\
China & 1.40 \\
USA & -0.58 \\
Europe & -0.57 \\
Asia except China & -1.46 \\
Other Countries & 0.66 \\
& \\
\hline
\end{tabular}

Table 4: Cumulative welfare change by region compared to free trade in billion US\$

Chinese trade restrictions alter market prices both inside and outside the People's Republic. Table 4 presents $\Delta W_{r}$, the discounted marshallian welfare change until 2020 by region $r$ compared to a free trade situation. $\Delta W_{r}$ is measured in billion US $\$$. The free trade scenario is calculated by dropping China's export barriers from 2014 onwards. All other parameters, such as Chinese production or demand prognoses, remain unchanged. Producer and consumer surplus under the assumption of free trade can then be compared with the baseline results.

Sustaining export restrictions yields welfare gains of 1.4 billion US\$ for the People's Republic. The Other Countries (OtC) region also experiences a positive welfare effect. It encompasses a number of nations with notable Rare Earth deposits (Australia, Canada, South Africa, Greenland) which gain from higher prices outside China. The USA, Europe, and the rest of Asia suffer from Chinese export barriers. While welfare losses are around 580 million US\$ in the US and Europe, the rest of Asia loses 1.46 billion US\$. Welfare effects outside China add up to -1.96 billion US $\$$. Export restrictions reduce overall welfare by 0.57 billion US $\$$. 


\section{$5.2 \quad$ Introducing Recycling}

Recycling costs were assumed to be prohibitive in the baseline scenario. This subsection investigates how a reduction of recycling costs would affect model outcomes. The application phosphors, in which Rare Earths are used to colorize TV screens or fluorescent lamps, was chosen as an example. Products in this application exhibit a high potential for recycling of Rare Earths, compared to other uses. The linear recycling costs $c R e c_{r, t}^{a p p}$ are assumed to be 115 US\$ per kg of Rare Earths contained in phosphors. That corresponds to $50 \%$ of the price of a $\mathrm{kg}$ of Rare Earths used in phosphors in 2014. Thus, recycling costs are assumed to be rather low.

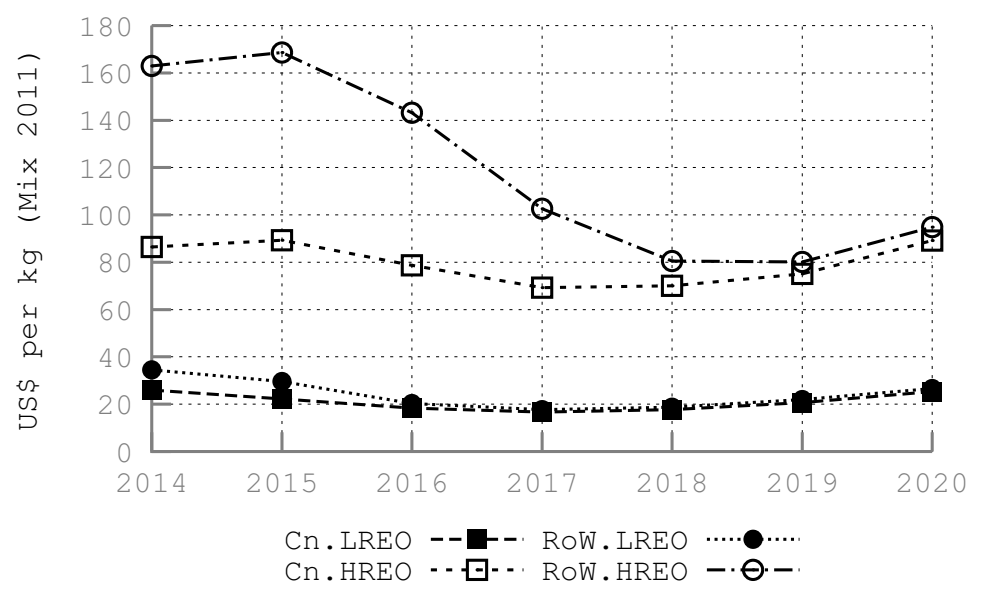

Figure 11: Prices of LREO and HREO in China and the rest of the world in US\$ per $\mathrm{kg}$ with recycling of phosphors.

Assuming costs of 115 US\$ per kg of Rare Earths recycled from phosphors implies high recycling rates in 2014 and 2015. 64\% of phosphors available are recycled in the US in 2014. The rate declines to $53 \%$ in 2015 and $14 \%$ in 2016 . Recycling as a supply of Rare Earths is crowded out by new producers of primary raw materials in 2017 already.

Figure 11 displays the prices for Light and Heavy Rare Earth Oxides inside as well as outside China in US\$ per kg. Prices for LREO remain virtually unchanged. Only minor quantities of Light Rare Earths are used to fabricate phosphors, which is why recycling them does not affect LREO prices.

Introducing recycling lowers HREO prices notably, in particular in 2014 and 2015. Additional supply of Heavy Rare Earths reduces the prices of HREO outside China from 255 to 163 US\$ per $\mathrm{kg}$ in 2014 and from 254 to 169 US\$ in 2015 . No major effects of recycling Rare Earths from phosphors is visible thereafter.

Two conclusions can be drawn from these results. Firstly, introducing recycling has the most significant effects if it takes place in the short run. The additional supply affects 
market prices strongly while investment lags constraint the entry of non-Chinese mines. Secondly, assuming constant marginal costs of recycling can lead to large and quick shifts in recycling rates. Therefore, results derived under this assumption need to be interpreted carefully.

\section{Sensitivity Checks}

Using a dynamic partial equilibrium model to analyze metal markets is a novel approach. Applying such a model on Rare Earths is novel as well. Comprehensive sensitivity analyses are important to assess the robustness of the results. Therefore, a number of Monte Carlo Simulations are conducted. The sensitivity of the results with respect to the following parameters is investigated: the price elasticity of demand $\epsilon_{t}$, the demand prognoses $\Delta_{r, t}^{r e a, a p p}$, the parameters quantifying the investment cost function $\xi$ and $\varphi$, and the cost data $c I \tilde{v}^{m n}$ and $c^{m n}$.

Except for $c \operatorname{In} \tilde{v}^{m n}$ and $c^{m n}$, which are analyzed jointly, each of the parameters is assessed in an individual Monte Carlo Simulation. A triangular-distributed random variable $X$ with a lower limit of 0.75 , an upper limit of 1.25 , and mode of 1 is used in the simulations. For $\xi$ and $\varphi$, the lower limit is decreased to 0.5 and the upper limit raised to 1.5, reflecting the uncertainty about these parameters. 1000 samples are drawn from the distribution and the realizations are multiplied with the corresponding parameter. For each model run, the difference between non-Chinese and Chinese prices of Rare Earths in per cent $\delta p D_{t}$ are calculated. For each Monte Carlo Simulation, the confidence intervals for $\delta p D_{t}$ are presented together with status-quo outcomes.

$$
\delta p D_{t}=\left(\frac{\sum_{a p p, r e o, r} \mathbf{D}_{r, t}^{r e o, a p p} \cdot \mathbf{p} \mathbf{D}_{R o W, t}^{r e o}}{\sum_{a p p, r e o, r} \mathbf{D}_{r, t}^{r e o, a p p} \cdot \mathbf{p} \mathbf{D}_{C n, t}^{r e o}}-1\right) \cdot 100
$$

Figure 12 (a) shows the 2.5\% percentile (Q2.5), status-quo values, and 97.5\% percentile (Q97.5) of $\delta p D_{t}$ in the Monte Carlo Simulation for the price elasticity of demand $\epsilon_{t}$. Results are not very sensitive to the assumption on $\epsilon_{t}$. Price difference reacts most strongly to changes in $\epsilon_{t}$ up until 2016. The $95 \%$ confidence in this year is $[37.3,44,8]$. Investment lags limit market entry in these years, which makes supply inelastic. Markets are cleared by reducing demand. The price elasticity determines the magnitude of price changes needed to clear the markets.

The confidence interval for the simulations for the demand prognoses $\Delta_{r, t}^{r e a, a p p}$ are displayed in figure $12(\mathrm{~b})$. The price difference between the rest of the world and China 


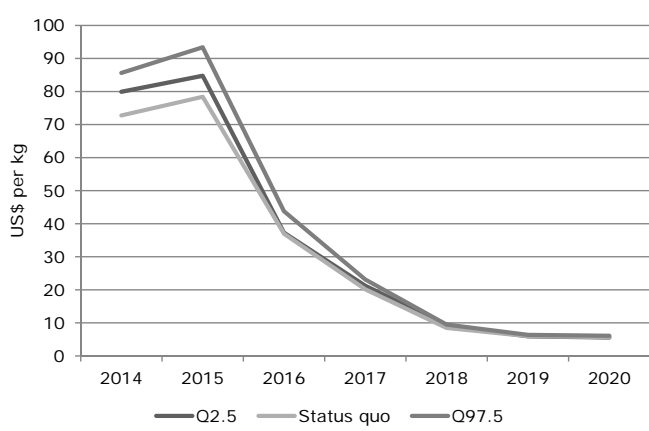

(a)

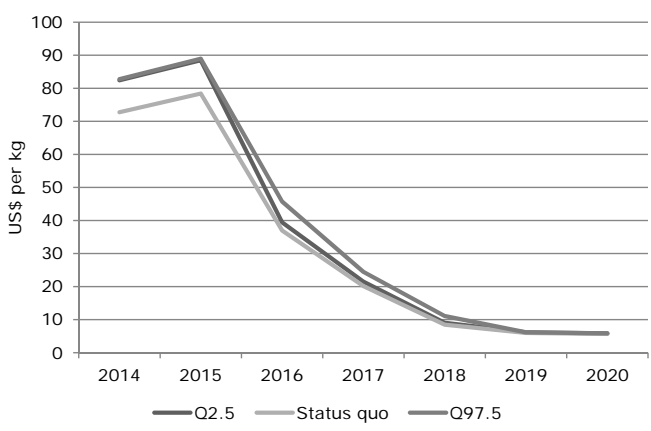

(c)

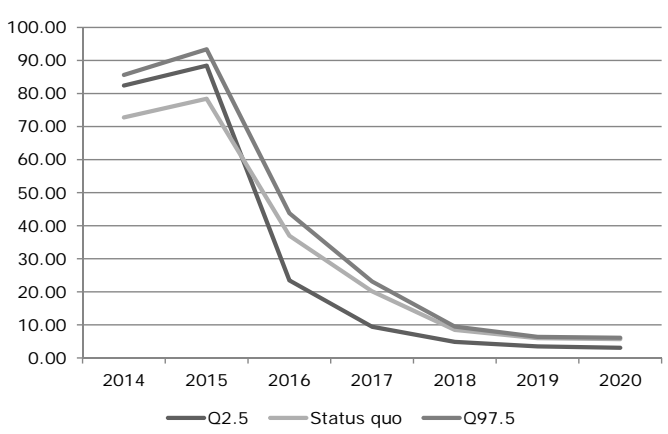

(b)

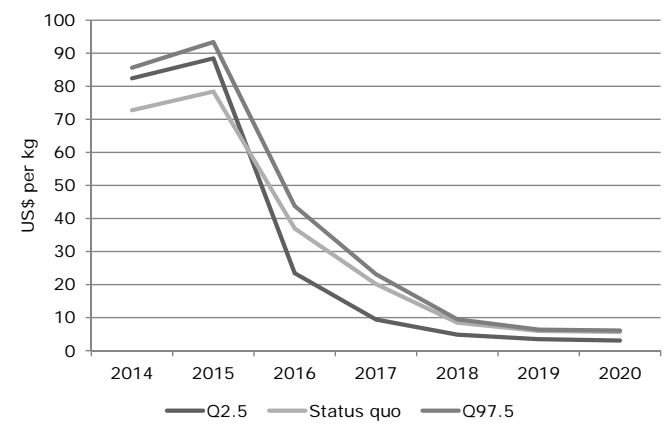

(d)



(e)

Figure 12: $2.5 \%$ percentile, status-quo values, and $97.5 \%$ percentile for the sensitivity checks. (a) Price elasticity of demand $\left(\epsilon_{t}\right)$, (b) Demand prognoses $\left(\Delta_{r, t}^{r e o, a p p}\right)$, (c) Share of linear part in investment cost function $(\xi)$, (d) Degree of convexity of investment costs $(\varphi),(\mathrm{e})$ Investment $\operatorname{costs}\left(c \tilde{I n v}^{m n}\right)$ and extraction costs $\left(c^{m n}\right)$ 
shows some sensitivity to demand shocks. The confidence interval is around $55 \%$ of $\delta p D_{t}$ in the status-quo from 2016 to 2020 . Take 2016 as an example. The $95 \%$ confidence interval of $\delta p D_{2016}$ is $[23.5,43.8]$, the status quo value is 37.0. The width of the confidence interval (20.3) corresponds to $55 \%$ of the status-quo value. The sensitivity to demand shocks is not a surprising result. Positive demand shocks make export restrictions more effective, negative shocks make them less binding and reduce the necessity for new investment. Thus, the sensitivity to demand shocks reflects characteristics of the market rather than flaws of the model.

Figure $12(\mathrm{c})$ and (d) display the sensitivity of $\delta p D_{t}$ to changes in the two parameters of the investment cost function $\xi$ and $\varphi$. Recall that the upper limit is larger than in the other Monte Carlo Simulations (1.5 compared to 1.25) and the lower limit is smaller (0.5 compared to 0.75). Nevertheless, price differences are insensitive to the assumptions on $\xi$ and $\varphi$.

The confidence interval for $\delta p D_{t}$ in the simulation for investment and extraction costs is shown in figure 12 (e). As in all Monte Carlo Simulations, the model's results remain qualitatively unchanged. Sensitivity of the results can be observed mostly between 2016 and 2018, when expansion of non-Chinese capacity is particularly strongly. The $95 \%$ confidence intervals are $[31.4,50.3]$ in 2016, [19.7,26.8] in 2017 and $[8.3,14.8]$ in 2017. These results also reflect uncertainties about costs estimates underlying the calibration.

\section{Conclusions}

This paper presents the METal ResOurce (METRO) model, a novel dynamic partial equilibrium model which can be used to depict a large number of metal markets. It covers the whole physical life cycle of a metal, from extraction to recycling or disposal. It is, to my knowledge, the first partial equilibrium model for metal markets with endogenous investment in mining capacities. The first application of the METRO model are the markets for Rare Earth Elements. Therefore, a novel dataset on Rare Earth mines was compiled to calibrate the model.

The METRO model is employed to analyze some key developments in the supply, demand, and prices of Rare Earths. Chinese export restrictions are assumed to remain unchanged in these simulations. Four results should be emphasized: (1) Non-Chinese supply is expected to grow strongly until 2020, in particular from 2016 to 2018. About $50 \%$ of Rare Earths are mined outside China in 2020. (2) Prices for Rare Earths drop considerably from 2016 on. (3) Differentiating between Heavy and Light Rare Earths is 
important. Heavy Rare Earth prices outside China exceed those in the People's Republic more strongly and more persistently. (4) Recycling has the strongest effects on price levels if it can be introduced while market entry of non-Chinese suppliers is still limited by investment lags.

Extensive robustness checks indicate that the results are qualitatively insensitive to changes in key assumptions. Shocks on costs as well as demand shocks are more influential than the parameterization of investment costs or the demand elasticity. While the qualitative interpretations are very robust, quantitative results need to be interpreted with care given the uncertainty on future demand or costs.

The METRO model allows for extension in several directions. Non-Chinese mines are assumed to be price takers. If a small number of new firms is able to enter the market and face an inelastic demand, they might be able to exert market power. Thus, the model could be extended by allowing for strategic behavior. ${ }^{5}$ Introducing trade costs can emphasize the spatial dimension of the model. The METRO model can also be extended by introducing technical progress, which is not negligible in the long run (Aydin and Tilton, 2000; Garcia et al., 2001). Not least, the model can be calibrated to a large number of other metals.

\section{References}

Adelman, M. A. (1990). Mineral Depletion, with Special Reference to Petroleum. Review of Economics and Statistics, 72(1):1-10.

Agostini, C. A. (2006). Estimating Market Power in the US Copper Industry. Review of Industrial Organization, 28(1):17-39.

Assaf, S. A. and Al-Hejji, S. (2006). Causes of delay in large construction projects. International Journal of Project Management, 24(4):349-357.

Aydin, H. and Tilton, J. E. (2000). Mineral endowment, labor productivity, and comparative advantage in mining. Resource and Energy Economics, 22(4):281-293.

Cairns, R. D. (2001). Capacity Choice and the Theory of the Mine. Environmental and Resource Economics, 18(1):129-148.

Demailly, D. and Quirion, P. (2008). European Emission Trading Scheme and competitiveness: A case study on the iron and steel industry. Energy Economics, 30(4):2009-2027.

Dirkse, S. P. and Ferris, M. C. (1995). The PATH Solver: A Non-Monotone Stabilization Scheme for Mixed Complementarity Problems. Optimization Methods and Software, $5(2): 123-156$.

Dudka, S. and Adriano, D. C. (1997). Environmental Impacts of Metal Ore Mining and Processing: A Review. Journal of Environmental Quality, 26(3):590-602.

\footnotetext{
${ }^{5}$ Thanks to Sherman Robinson for pointing this out.
} 
E3Mlab (2010). PRIMES Model.

EU Commission (2010). Critical raw materials for the EU. Report of the Ad-hoc Working Group on defining critical raw materials. Technical report.

EU Commission (2011). A resource-efficient Europe Flagship initiative under the Europe 2020 Strategy. COM(2011) 21. Technical report.

Fisher, F. M., Cootner, P. H., and Baily, M. N. (1972). An Econometric Model of the World Copper Industry. Bell Journal of Economics, 3(2):568-609.

Fisher, L. and Owen, A. (1981). An economic model of the US aluminium market. Resources Policy, 7(3):150-160.

Garcia, P., Knights, P. F., and Tilton, J. E. (2001). Labor productivity and comparative advantage in mining:: the copper industry in Chile. Resources Policy, 27(2):97-105.

Gielen, D. and Moriguchi, Y. (2002). CO2 in the iron and steel industry : an analysis of Japanese emission reduction potentials. Energy Policy, 30(10):849-863.

Gupta, S. (1982). An econometric analysis of the world zinc market. Empirical Economics, $7(1): 213-237$.

Hartwick, J. M., Kemp, M. C., and van Long, N. (1985). Set-up costs and the theory of exhaustible resources. Papers of the Regional Science Association, 56(1):99-111.

Hatch, G. (2012a). August 2012 Updates To The TMR Advanced Rare-Earth Projects Index.

Hatch, G. (2012b). The Final Chinese Rare-Earth Export-Quota Allocations For 2012.

Hatch, G. (2012c). The First Round Of Chinese Rare-Earth Export-Quota Allocations For 2013.

Hatch, G. (2013a). The Second Round of Chinese Rare-Earth Export-Quota Allocations for 2013 .

Hatch, G. (2013b). TMR Advanced Rare-Earth Projects Index. July 24, 2013 Update. Technical report.

Holland, S. P. (2003). Set-up costs and the existence of competitive equilibrium when extraction capacity is limited. Journal of Environmental Economics and Management, 46(3):539-556.

Hotelling, H. (1931). The Economics of Exhaustible Resources. Journal of Political Economy1, 39(2):137-175.

Hurst, C. (2010). Chinas Rare Earth Elements Industry: What Can the West Learn? Technical report, Institute for the Analysis of Global Security.

Kingsnorth, D. J. (2012). The Global Rare Earths Industry: A Delicate Balancing Act. Technical report, Deutsche Rohstoffagentur.

Kingsnorth, D. J. (2013). Can Chinas Rare Earths Dynasty Survive. Technical report.

Korinek, J. and Kim, J. (2010). Export Restrictions on Strategic Raw Materials and Their Impact on Trade and Global Supply. Trade Policy Working Papers. OECD Publishing.

Lanz, B., Rutherford, T. F., and Tilton, J. E. (2013). Subglobal Climate Agreements and Energy-intensive Activities: An Evaluation of Carbon Leakage in the Copper Industry. World Economy, 36(3):254-279. 
Mackenzie, W. and Cusworth, N. (2007). The Use and Abuse of Feasibility Studies. In AusIMM Project Evaluation Conference, Melbourne, Australia. Australasian Institute of Mining and Metallurgy.

Noort, D. J. and Adams, C. (2006). Effective Mining Project Management Systems. In International Mine Management Conference. Australasian Institute of Mining and Metallurgy.

Pothen, F. and Fink, K. (2013). The Political Economy of China's Export Restrictions on Rare Earth Elements. Technical report, Unpublished Work.

Rudenno, V. (2009). The Mining Valuation Handbook. Mining and Energy Valuation for Investors and Management. Wrightbooks, 3rd edition.

Schüler, D., Buchert, M., Liu, R., Dittrich, S., and Merz, C. (2011). Study on Rare Earths and Their Recycling. Öko-Institut, Darmstadt.

SCIO (2012). Situation and Policies of China's Rare Earth Industry. Technical report.

Slade, M. E. (1980). The effects of higher energy prices and declining ore quality: Copperaluminium substitution and recycling in the USA. Resources Policy, 6(3):223-239.

Technology Metals Research (2012). TMR Advanced Rare-Earth Projects Index. July 6, 2012 Update. Technical report.

Tse, P.-K. (2011). Chinas Rare-Earth Industry. Technical report, U.S. Geological Survey Report 20111042.

UNEP (2011). Recycling Rates of Metals. A Status Report. Technical report.

U.S. Department of Energy (2011). Critical Materials Strategy. Technical report.

U.S. Geological Survey (2011). Rare Earth Elements. End Use and Recyclability. Technical report, U.S. Geological Survey.

U.S. Geological Survey (2012a). Global Rare Earth Oxide (REO) Production Trends. Technical report.

U.S. Geological Survey (2012b). Mineral Commodity Summaries. Rare Earths. Technical report.

Winters, L. (1995). Liberalizing European steel trade. European Economic Review, 39(34):611-621.

WTO (2012). China Measures Related to the Exportation of Rare Earths, Tungsten and Molybdenum. Request for Consultations by the United States. Technical report, WT/DS431/6.

Wübbeke, J. (2013). Rare earth elements in China: Policies and narratives of reinventing an industry. Resources Policy, 38(3):384-394. 